\title{
Raising the level of medical gerontology: Evaluation of the European Academy for Medicine of Ageing course
}

\author{
J-P. Michel for the Group of European Professors of Medical Gerontology ${ }^{1}$ \\ Department of Geriatrics, Genève University Hospital, Genève, Switzerland
}

\begin{abstract}
The two-year EAMA course was established in 1995 by the Group of European Professors in Medical Gerontology (GEPMG) with the aim of raising the global standard of medical gerontology in (chiefly) European junior faculties. To determine the impact of this new course, a careful evaluation was made on each of its various goals. Thirty-five and thirty-eight students, selected by national professional societies from 15 different European countries, plus Israel and Mexico, took part in the first two one-week sessions. On the basis of daily and weekly evaluations, performed by both students themselves and teachers, we can say that the first two EAMA sessions succeeded in reaching their main goals: enhancing and updating knowledge, better identifying deficiencies, improving skills in gathering data, establishing priorities, expressing important messages, leading discussions, and creating an international network in medical gerontology. The next two EAMA sessions will hopefully confirm these conclusions.

(Aging Clin. Exp. Res. 9: 224-230, 1997)

o 1997, Editrice Kurtis
\end{abstract}

\section{INTRODUCTION}

After drawing up an exhaustive inventory of geriatrics teaching in Europe, the Group of European Professors of Medical Gerontology (GEPMG) established priorities aimed at raising the global level of "medical gerontology" (1). In particular, it appeared important to cope with three intermediate goals: 1) providing up-to-date education and training in medical gerontology; 2) developing a core curriculum in medical gerontology: knowledge, skills and attitudes; and 3) holding special workshop courses and summer schools for junior faculties.

With a view to implement these aims, the European Academy for Medicine of Ageing (EAMA) was founded by the GEPMG in 1993 with the technical and financial support of the Foundation K. Boesch, Sion (Switzerland). In 1994, the EAMA launched the project of a two-year course in medical gerontology, composed of four one-week sessions of education and training, addressed to junior faculties and focused on the main topics of gerontology and geriatrics (Table 1). The EAMA course was set up with the following objectives:

- enhancing and updating knowledge, and identifying deficiencies;

- improving knowledge and skills for gathering data, achieving critical interpretation of information, establishing priorities, expressing important messages, leading discussions, giving lectures, raising new research ideas; and

- creating an international network in medical gerontology, and promoting the exchange of knowledge, know-how and experiences between various age generations of geriatricians working in countries with different socioeconomic levels, culture and ethical mind set (2).

The teaching methodology of the EAMA sessions

\footnotetext{
${ }^{1}$ M. Michel, J-P. Michel, H.B. Stahelin and the Group of European Professors of Medical Gerontology: E. Beregi, G. Crepaldi, S. Duursma, J-P. Emeriau, J. Grimley-Evans, B. Steen, and A. Ruiz-Torres.

Key words: Geriatrics, gerontology, medical education, teaching evaluation, training.

Correspondence: J-P. Michel, M.D., Département de Gériatrie, Hôpitaux Universitaires de Genève, Route de Mon-Idée CH-1226 Thônex-Genève, Switzerland.

Received and accepted November 13, 1996.
} 
Table 1 - Session, dates and topics of the first EAMA course.

January 17-21, 1995

August 22-26, 1995

January 23-27, 1996

August 20-24, 1996
Infection, nutrition and immunity in aging: from molecular biology to clinical management

Mobility disorders, assessment, scientific basis of rehabilitation and outcome in the elderly

The aging brain and related disorders: from the scientific basis to the social response

Circulation and aging: fundamental aspects, prevention and treatment is based on a planned series of "junior faculties" working groups, plenary report of discussions, lectures by "junior faculties", state-of-the-art lectures by "teachers", plenary debate on various topics and tutorials (3-6) (Table 2).

To evaluate if the EAMA course was reaching its goals, two kinds of evaluation were performed during and after each session (daily and weekly evaluations) $(7,8)$. Results of these evaluations by the junior faculties (also called below "students") and by the professors (also called below "teachers") of the first two one-week sessions (focused on "nutrition, immunity and infection" held in January 1995 and on "rehabilitation and scientific outcomes" held in August 1995) are presented in Table 3.

\section{SUBJECTS AND METHODOLOGY}

\section{The students}

During 1994, the EAMA course was advertised by different means, including direct contact with the GEPMG members' own national societies of geron- tology and geriatrics (France, Hungary, Italy, The Netherlands, Spain, Sweden, Switzerland, United Kingdom). A large board of scientific members helped GEPMG members to disseminate information about the course in other European national societies (Belgium, Germany, Finland, Norway, Poland, Romania, Czechkia). Contacts were also established with GEPMG members' international societies (International Gerontological Association and International Psychogeriatrics Association). Written advertisements were published in Age and Ageing, Aging Clinical and Experimental Research, and Facts and Research in Gerontology.

More than 50 students' applications were analyzed by the GEPMG. For each applicant, personal contacts were established to explain the EAMA's training goals. Depending on the acceptance of these goals, contacts with the national professional society of geriatrics were made to discuss the applicant's future. Identical criteria permitted to select applicants according to clinical experience, academic curricula (number of publications in peer review journals, re-

Table 2 - Teaching methodology of the EAMA course.

\begin{tabular}{|c|c|c|c|}
\hline Exercise & Time & Definition & Goals \\
\hline Working group discussion & $\begin{array}{l}60 \text { minutes followed by an } \\
\text { oral/visual report in plenary } \\
\text { session and comments/discussions } \\
\text { among students and teachers }\end{array}$ & $\begin{array}{l}\text { Students work together without } \\
\text { any teacher on a subject with a } \\
\text { different animator and reporter } \\
\text { for each working group }\end{array}$ & $\begin{array}{l}\text { Leading a group discussion, } \\
\text { gathering scientific knowledge, } \\
\text { establishing attitudes/priorities, } \\
\text { selecting take-home messages }\end{array}$ \\
\hline Students' lectures & $\begin{array}{l}15 \text { minutes, followed by } \\
\text { comments/discussions among } \\
\text { students and teachers }\end{array}$ & $\begin{array}{l}\text { Summary of important data } \\
\text { concerning both knowledge and } \\
\text { attitudes in a specific field }\end{array}$ & $\begin{array}{l}\text { Train the students to prepare and } \\
\text { give top-quality presentations with } \\
\text { up-to-date bibliography, valuable } \\
\text { visual material and useful contents }\end{array}$ \\
\hline Teachers' lectures & $\begin{array}{l}45 \text { minutes followed by } \\
\text { questions from students } \\
\text { and teachers }\end{array}$ & $\begin{array}{l}\text { State-of-the-art lecture of very } \\
\text { high quality as regards contents, } \\
\text { form and presentation }\end{array}$ & $\begin{array}{l}\text { Model of top-quality scientific } \\
\text { presentations: up-to-date data, } \\
\text { excellent oral presentation and } \\
\text { high-standard visual aid }\end{array}$ \\
\hline Plenary session debate & 60 minutes & $\begin{array}{l}\text { Transcultural debate on therapy } \\
\text { or ethics }\end{array}$ & $\begin{array}{l}\text { Participating in debates, upholding } \\
\text { attitudes and accepting opposite } \\
\text { opinions }\end{array}$ \\
\hline
\end{tabular}


M. Michel, J-P. Michel, H.B. Stahelin, et al.

Table 3 - Programs of the first two EAMA sessions.
Infection, nutrition and immunity in aging:
Mobility disorders, assessment, scientific basis and
From molecular biology to clinical management
outcomes of rehabilitation

Students' lectures

Protein-calorie of malnutrition Spinal stenosis

Specific deficiencies of malnutrition Risks and benefits of NSAIDs

Infections in the elderly: Metabolic responses Rehabilitation after hip fracture

Rehabilitation after myocardial infarction

Students' group discussions

$\begin{array}{ll}\text { Markers of aging } & \text { Osteoporosis: Who should be treated? } \\ \text { Immunology of the elderly: Clinical aspects } & \text { Risk factors of falls, prevention of fracture } \\ \text { Nutritional requirements in the elderly } & \text { Management of skeletal metastasis } \\ \text { Prevention of malnutrition (at home and in institutions) } & \text { Osteomyelitis, gout, polyneuropathy ... } \\ & \begin{array}{l}\text { Effects of hormone replacement on bones } \\ \text { Exercise training: Benefits and risks }\end{array} \\ & \text { Setting objectives for rehabilitation }\end{array}$

Plenary discussions

Malnutrition: Choosing a treatment

Osteoporosis: Choosing a treatment

Ethics of enteral or parenteral feeding

Measures of outcomes in rehabilitation

State-of-the art lectures by teachers

Normal and pathological aging Physiopathology of osteoporosis

Immunology of aging Physiopathology of osteoarthritis

Hospital malnutrition Mobility and muscles

Flu and anti-pneumococcal vaccinations $\quad$ Scientific basis and effectiveness of rehabilitation

Evening lectures

A greying planet

Education strategies in chronic diseases

How to write a seminal paper

How to review a scientific article

search and teaching involvement), current working position, academic future, support of the national professional society, possibility to obtain grants and promise to attend the four one-week sessions of the EAMA course.

Thirty-five and thirty-eight students attended the first two sessions (Table 4). Only 26 of them were evaluated twice. Seven students missed the first evaluation ( 2 because they were involved in a press conference at the time of evaluation, 5 because their involvement in the session was too discreet to be evaluated). For that reason, 3 of 5 of these students dropped out after the first session, after which 8 new students were accepted.

\section{The teachers}

Most of them were chairpersons of geriatric clinics in their own country and members of the GEPMG, and were involved in the organization of the EAMA
Table 4 - Origin of students participating in the first EAMA two-week sessions.

\begin{tabular}{clc}
\hline First Session & Countries & Second Session \\
\hline 1 & Austria & 1 \\
4 & Belgium & 4 \\
1 & Denmark & 0 \\
1 & Finland & 1 \\
5 & France & 5 \\
3 & Germany & 5 \\
1 & Israel & 2 \\
0 & Mexico & 1 \\
5 & The Netherlands & 5 \\
2 & Poland & 2 \\
1 & Romania & 1 \\
1 & Spain & 1 \\
3 & Sweden & 3 \\
6 & Switzerland & 6 \\
1 & Ukraine & 1 \\
Total $=35$ & & Total $=38$
\end{tabular}


course. The other professors (non-GEPMG) were selected for their reputation in the general (geriatrics) or specific topic (specialists) addressed by the session (Table 5). The teachers used to meet before each session in order to specify the goals of the teaching methodology, match their experiences, select messages, and evaluate the relevance of statements.

\section{Goals of the EAMA session evaluation}

The evaluations were carried out to appraise the benefit and appropriateness of the session/course: 1) for students: to ascertain their progress; 2) for teachers: to improve their teaching techniques; and 3) for organizers: to adjust the time-table of the sessions and focus on main gaps of knowledge or skills.

\section{Methodology of the EAMA session evaluation}

Two kinds of evaluation were made: 1) the daily evaluation was focused on students' and teachers' academic activities (the first were evaluated by both students and teachers, the second by students only); and 2) a questionnaire was proposed at the end of each session.

Evaluation criteria, defined at the beginning of each session, were the following:

- technique of presentation: including speaker's position, tone of voice, glance activity during lecture, hand gestures during speech, and visibility, clarity and comprehensibility of slides or transparencies;

- scientific level: including precise and up-to-date data from the international literature, source references clearly quoted at the bottom of visual documents, simplification of complex theories, thus showing a perfect understanding of the matter, and clear and simple presentation of arguments;

Table 5 - Origin of teachers participating in the first EAMA two-week sessions.

\begin{tabular}{clc}
\hline First Session & Countries & Second Session \\
\hline 0 & Canada & 1 \\
1 & France & 1 \\
0 & Germany & 1 \\
1 & Italy & 0 \\
1 & Malta & 0 \\
0 & The Netherlands & 1 \\
1 & Spain & 0 \\
1 & Sweden & 0 \\
3 & Switzerland & 3 \\
1 & United Kingdom & 2 \\
2 & The United States & 1 \\
Total $=11$ & & Total $=10$ \\
\hline
\end{tabular}

- take-home messages: able to summarize in a few words a complex theory, useful ideas or advice for daily practice and key items for better understanding of a concept;

- involvement in debates: including reformulating the argument to better debate, asking relevant questions, giving contradictory arguments supported by scientific and updated data; and

- global evaluation: corresponding to personal feelings at the end of a lecture and integration of individual satisfaction or discomfort.

The written questionnaire completed at the end of the week session permitted to evaluate the global organization of the session, the concordance between the students' goals and the specific contribution of the session, updating of knowledge, progress in understanding the aging process and pathology of old age, adaptation of attitudes, acquisition of new research ideas, and ability to expand the students' professional network.

\section{RESULTS}

Students' evaluation of the EAMA objectives

In the students' opinion, the EAMA objectives appeared:

- clear, easily intelligible, evident and perspicuous (100\%);

- realistic, facing facts (82\%); and

- relevant, important, pertinent and applicable (100\%).

Personal goals of students participating in the EAMA course

The students' primary goals were to increase knowledge $(56 \%)$ in the short term, to raise new research ideas (25\%) in the medium term, and both to establish a network (42\%) and to become a "professor" $(42 \%)$ in the long term.

\section{Evaluation of the organization of sessions}

The course was well perceived by the students, who scored both their own feelings about the sessions and the importance they attached to the various items (Table 6). The main criticism concerned the time distribution, e.g., not enough time for the working group sessions, not enough time for discussing the students' lectures, too compact a programme, too long working days, too short tea breaks and lunch times... The second complaint concerned the students-teachers relationship, and this was seriously considered by the teachers.

\section{Evaluation of the teaching methodology}


M. Michel, J-P. Michel, H.B. Stahelin, et al.

Table 6 - Global evaluation of the EAMA's sessions.

\begin{tabular}{lcc}
\hline & $\begin{array}{c}\text { Scores }>4 / 5 \\
(\%)\end{array}$ & $\begin{array}{c}\text { Importance of item } \\
(\%)\end{array}$ \\
\hline $\begin{array}{l}\text { Global evaluation } \\
\text { Atmosphere }\end{array}$ & 96 & 100 \\
\hline $\begin{array}{l}\text { Functional collaboration } \\
\text { Teacher/student }\end{array}$ & 61 & 96 \\
Student/student & 91 & 100 \\
Teacher/teacher & 71 & 91 \\
\hline Teachers' & & 100 \\
Accessibility & 78 & 100 \\
Number & 96 & 100 \\
Competence & 91 & 100 \\
\hline Various items & & 96 \\
Freedom of speech & 82 & 100 \\
Time distribution & 30 & \\
Documentation & 95 & \\
\hline
\end{tabular}

This new way of teaching top-level medical gerontology proved to be attractive to the students, who greatly appreciated the balance between up-to-date scientific lectures and the amount of practical discussions in the working groups. In particular, they found transcultural discussions during plenary sessions of great interest. Nevertheless, they asked for more "state-of-the-art lectures" by professors, advice on teaching methodology and information about costeffectiveness of care.

\section{Evaluation of teachers by students}

This evaluation was made daily during the first two EAMA sessions. In each session, one teacher scored less than 2 out of 5 at the global evaluation, while all the others scored over 4 out of 5 . The best scores were reached for scientific level, take-home messages and participation in the debate. Teachers' mean scores for the second session were higher than those of the first session.

\section{Evaluation of students by students}

This evaluation was also made daily during the first two EAMA sessions. At the first session, the students' scores were on average below 3 out of 5 (global evaluation, $50 \%$, technique of presentation, $45 \%$, scientific level, $60 \%$, take-home message, $71 \%$, and participation in the debate, $71 \%$ ). At the second session, the students' scores recorded a second time for and by the same 26 students, showed a clear increase in the level of scores, particularly that of global evaluation score (Fig. 1). Only 4 out of 26 students scored less at the second session compared to the first, only one scored below 3 out of 5 .

\section{Evaluation of students by teachers}

The same items of the students' evaluation were

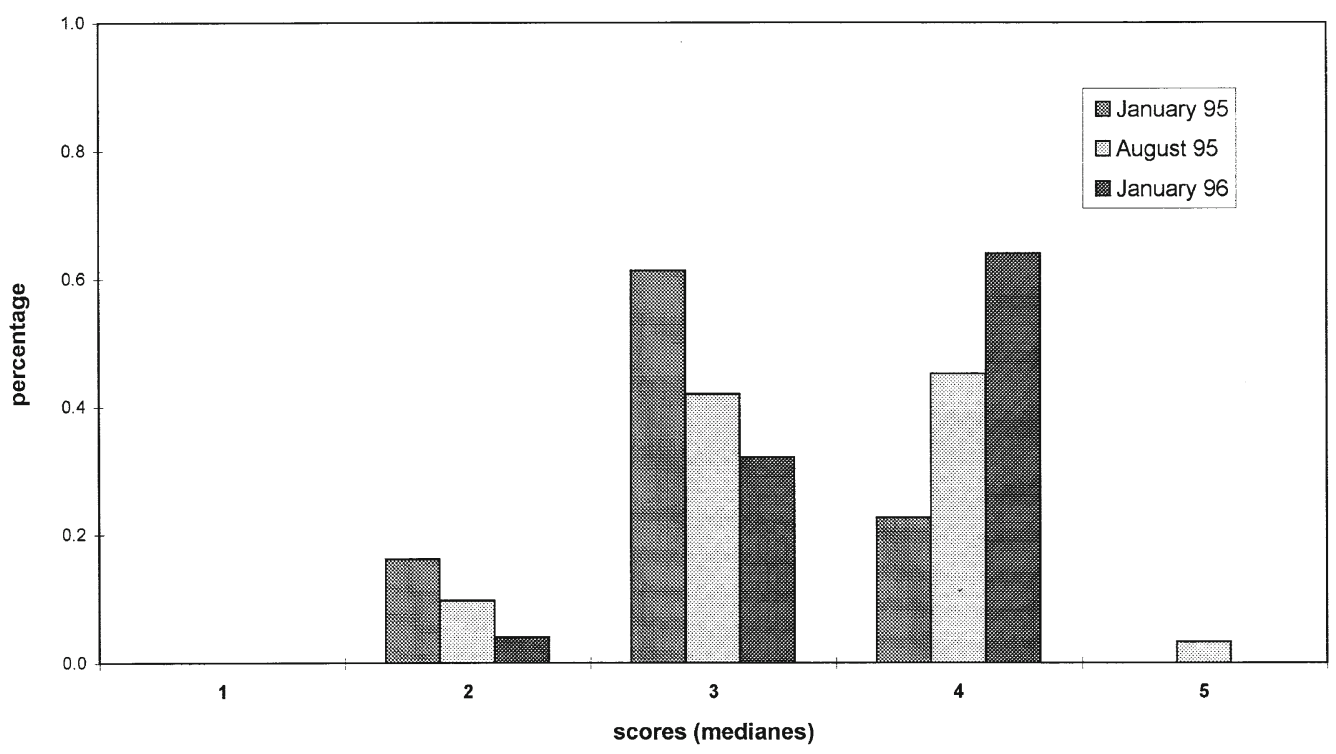

Figure 1 - EAMA - Students' global evaluation. 
assessed by the teachers. The latter appeared to be more generous than the students themselves. There was a good correlation between both students' and teachers' evaluations of the students (teacher grade $=0.39+0.96^{*}$ students, $r=0.80$ ) (Fig. 2).

Students' self-evaluation at the end of the second EAMA session

A written questionnaire was proposed at the end of the 2nd EAMA session, to evaluate the students' own perception of the main goals of the EAMA course (Table 6). Scores confirmed the progress accomplished by students in such fields as enhancing their knowledge, expressing messages, leading discussions, giving lectures, and establishing a collaborative network. Nevertheless, after the second EAMA session, it appeared that more work was necessary with regard to gathering data, gaining skills, establishing priorities, and raising research ideas.

\section{DISCUSSION}

The EAMA "adventure" was conceived by the GEPMG to raise the academic level of medical gerontology. At the beginning, the teachers' basic purposes were to strengthen and update knowledge of junior faculties, thereby enhancing their "academic" qualities and helping them to become the European professors of medical gerontology of the XXI century. Though not yet reached, these objectives were very well perceived by the "students", who competed to participate and to associate intellectual performances and fruitful collaboration within a European network of professionals.

The organization of sessions and the methodology of teaching were both harmonized in consideration of suggestions by students and teachers' experience and advice. However, a valuable mixture of group discussions with rotating animators and reporters, plenary discussions, students' and teachers' state-ofthe-art lectures, was found only after the first session. At the same time, evening lectures focusing on communicating, teaching and writing methodologies completed the main themes of the sessions.

The first evaluation of the teachers was more severe than the second. This seemed to be linked in the first place to the high expectations of the junior faculties attending the course, but also to incomplete information of non-GEPMG member teachers. Thus, in the future sessions, more careful consideration should be given to the very high scientific level of junior faculties attending the course as well as their strong demands for high educational standards.

The first evaluation of students by students was much discussed by the students themselves. They were dissatisfied with their first self-evaluation, which they considered of no value. For many of them, only the teachers were able to evaluate them. The second evaluation of students by students appeared to be very well correlated with the evaluation of students by teachers, who had less severe judgements. Only 4 of 28 students were more severely evaluated by the

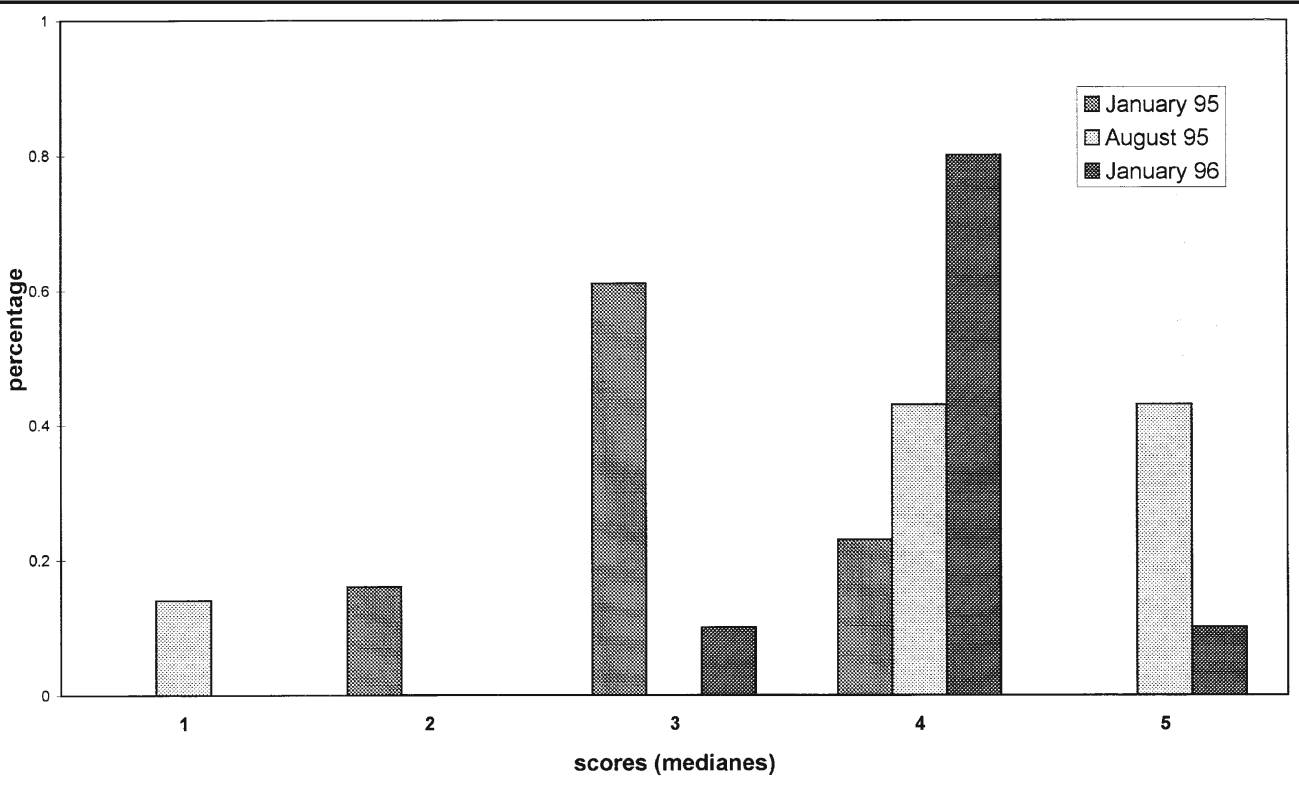

Figure 2 - EAMA - Teachers' global evaluation. 
teachers than by the other students. This comparison of results restored the students' confidence in the value of their self-evaluation.

The 1st and 2nd evaluations of students by students were very useful on several grounds: 1) the good correlation with the teachers' opinions raised the level of confidence in the evaluation methodology; 2) they proved that most of the students raised their global standard in medical gerontology; and 3) accordingly, the students were more motivated to continue working in the following EAMA sessions.

\section{CONCLUSIONS}

The students' self-evaluation of their own deficiencies prompted them to focus their efforts on several fields: gaining skills, gathering data, establishing priorities and raising new research ideas. Also, important progress was accomplished by the students in leading discussions, expressing messages, giving lectures and writing abilities. Likewise, it may well be that the EAMA sessions helped the teachers to improve their teaching abilities through confrontation with high-level students, probably their "future" colleagues.

In conclusion, we can say that the EAMA course succeeded in providing junior faculties with up-to-date education and training in medical gerontology, but also in raising the standard of communication skills and facilitating transcultural exchanges of knowledge, skills and attitudes among students and teachers.

The teachers took tremendous pleasure in enhancing the students' standard of achievement, and they are convinced of the necessity of organizing a second EAMA course. They are confident that these early EAMA students will be able to help them raise energy and funds to establish a continuing high-level course with a view to promoting higher standards for medical gerontology all over Europe, as well as in all countries which may be sensitive to the need for a better training of their future geriatric faculties.

\section{REFERENCES}

1. Group of European Professors of Medical Gerontology:Teaching Gerontology in Europe. Age Ageing 23: 179-181, 1994.

2. World Health Organization: Aging and Health: a programme perspective. Health of the elderly unit. World Health Organization, Executive Board, 95th session, Genève, 1995.

3. Guilbert J.J.: Educational handbook for health personnel. World Health Organization, Offset Publication 35, ed 6. Genève, 1992.

4. Harris T.L., Schwahn W.E.: Selected readings on the learning process. Oxford University Press, New York, 1961.

5. Knowles M.: The adult learner: a neglected species. Gulf Publishing Company, Houston, 1990.

6. Smith R.M.: Learning how to learn: applied theory for adults. Follett, Chicago, 1982.

7. Katz F.M.: Directives pour l'évaluation des programmes de formation des personnels de santé. World Health Organization, Offset Publication 38, Genève, 1978.

8. World Health Organization: Review and evaluation of specific programmes. Part 1: Health of the elderly. World Health Organization, Executive Board, 95th session, Genève, 1995. 